Brtt. J. prev. soc. Med. (1961), 15, 61

\title{
HOME LOCALITIES OF NATIONAL SERVICEMEN WITH RESPIRATORY DISEASE*
}

\author{
BY
}

\author{
S. ROSENBAUM
}

London

The standard method of comparing sickness in the Army in different regions is to calculate morbidity rates, viz. the ratios of cases to numbers at risk in those regions. When this is done for respiratory diseases in the United Kingdom the results follow to some extent the pattern of civilian experience for the same areas, as far as can be determined from such figures as are published.

A different aspect is investigated here, in that a soldier's home locality before enlistment is pinpointed, and the sickness rate, irrespective of where he is serving, including overseas, is related to his home. The prospect is that different liabilities to disease may be revealed on this basis. A number of factors that bear upon the findings are discussed.

\section{METHOD AND ReSULTS}

A one per cent. sample was taken of all admissions of National Servicemen for respiratory diseases in 1953. These admissions were to medical units in all theatres and consisted of the cases coded under Section VIII of the Manual (W.H.O., 1949) of the International Statistical Classification (Diseases of the Respiratory System) plus cases of asthma (say 2 per cent. of the respiratory diseases). It was an effectively random sample, being based on the soldier's Army number.

The possibility of calculating a sickness rate based on the home locality arose because the record of a recruit's medical examination on entry into the Army contained the name of the place where he was examined after registration for National Service, and this place was taken as the home locality. It was found that a comparison with the population as given by the Registrar General was unsatisfactory, as the catchment areas were not known. The most direct

- The material for this paper forms part of the work approved by the University of London for the award of the degree of Ph.D. comparison with numbers at risk would be with those passing through the same medical boards (some sixty in number) where they were examined after registration. This could not, in fact, be done for 1953 but throughout 1956 a sample (again effectively random) was taken of the numbers of National Servicemen passing through the various medical boards. Numbering some 2,600, these were the best possible base for relating the cases of respiratory disease which had come from those boards. The boards have been grouped fairly arbitrarily into regions, and the rates expressed as percentages of the national rate in Table I (they are also plotted on the map in Fig. 1, overleaf).

TABLE I

CASES OF RESPIRATORY DISEASE AMONG NATIONAI SERVICEMEN IN 1953 RELATED TO NUMBERS PASSING THROUGH THE MEDICAL EXAMINATION BOARDS IN THE PLACES WHERE THEY ENLISTED

\begin{tabular}{lll|c|c}
\hline & & \multicolumn{2}{c}{ Percentage of National Rate } \\
\cline { 3 - 4 } \multicolumn{2}{c|}{ Region } & & Sick Persons & Spells of Sickness \\
\hline Scotland & $\ldots$ & $\ldots$ & 130 & 126 \\
Midlands & $\ldots$ & $\ldots$ & 118 & 131 \\
London $\ldots$ & $\ldots$ & $\ldots$ & 115 & 111 \\
North-East & $\ldots$ & $\ldots$ & 104 & 100 \\
North-West & $\ldots$ & $\ldots$ & 100 & 101 \\
South-East & $\ldots$ & $\ldots$ & 88 & 85 \\
Wales $\ldots$ & $\ldots$ & $\ldots$ & 80 & 75 \\
South $\ldots$ & $\ldots$ & $\ldots$ & 77 & 75 \\
South-West & $\ldots$ & $\ldots$ & 77 & 63 \\
East Anglia & $\ldots$ & $\ldots$ & 65 & 169 \\
\hline * Glasgow & $\ldots$ & $\ldots$ & 175 & 155 \\
* Liverpool & $\ldots$ & $\ldots$ & 160 & $\mathbf{1 1 0}$ \\
* Birmingham & $\ldots$ & $\ldots$ & 114 & 68 \\
* Manchester & $\ldots$ & $\ldots$ & 59 & \\
\hline
\end{tabular}

* Individual towns large enough to be worth quoting.

The results are given in terms both of persons ill and of spells of sickness during 1953. The method of sampling (by Army number) ensured that the correct proportion of repeated illness was included, without the need to trace personal histories. 


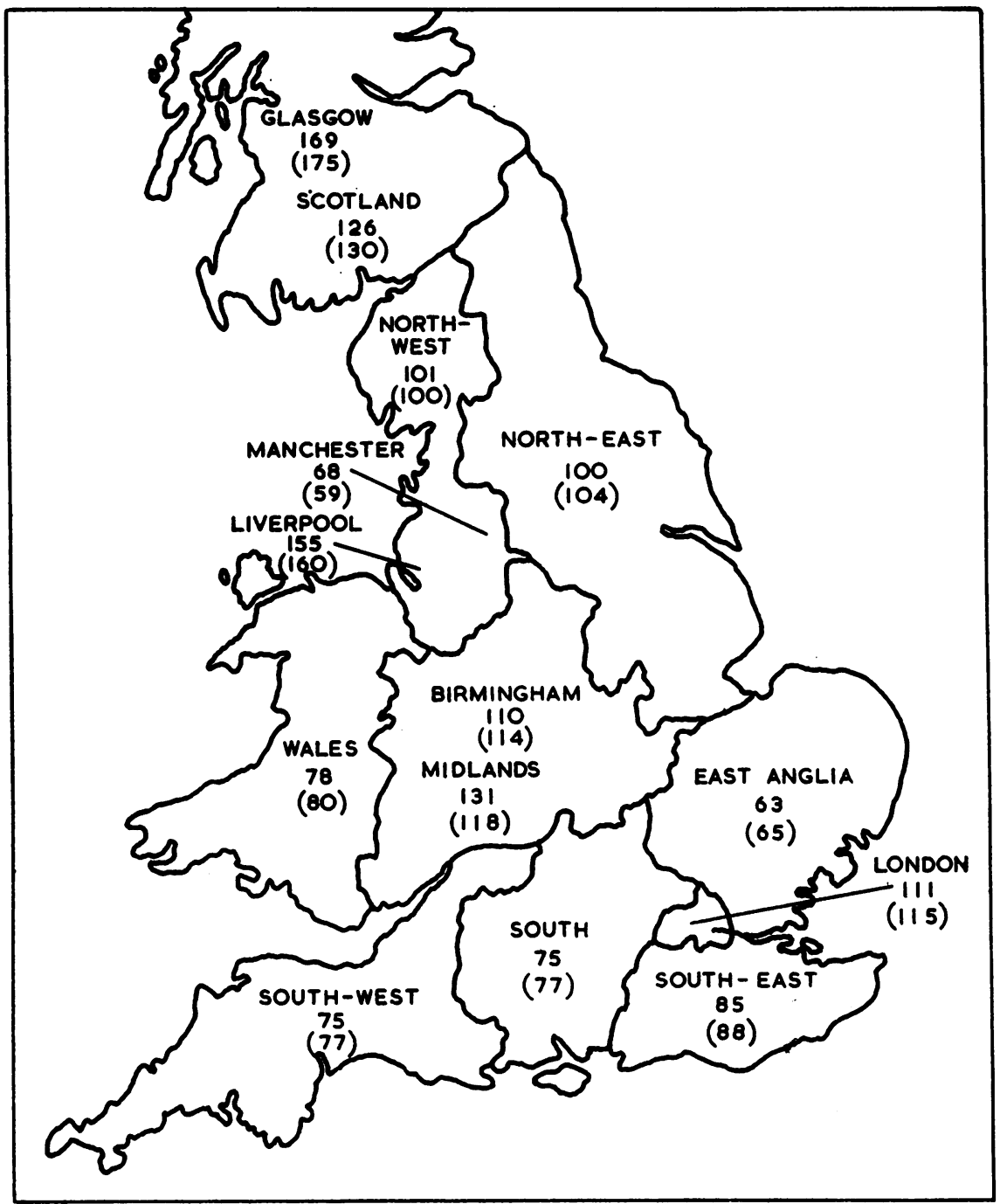

Fic. 1.-Cases of respiratory disease among National Servicemen in 1953 related to the numbers passing through the medical examination boards in the places where they enlisted. Regions expressed as percentages of the national rate.

There were of course difficulties in the regional grouping, a typical one being with regard to Leyton, which served both the East London boroughs and Essex; in this particular case the results were split.

The percentages in Table $I$ are very plausible, in that they suggest a pattern of greater urban-industrial morbidity although they do not differ significantly from the average, considered as a group. Actually the selected group of Glasgow, Liverpool, London, and the Midlands does, with a figure of 130 per cent. in respect of persons, show up as significantly different from the rest of the country, at 82 per cent. (in respect of spells of sickness the figures are 132 per cent. as against 79 per cent.); but pre-selection of this sort is a rather suspect procedure without the strongest justification for choosing these particular areas. It may be that the investigation of further cases will confirm the pattern already indicated, except in minor details: that is, the apparent effect of an industrial home background on subsequent respiratory complaints during National Service.

Reference must be made to the comparatively low (though not significantly low) figure for Manchester. 
This city presumably drew into its orbit recruits from neighbouring districts, and the numbers examined in the sample far exceeded those from Birmingham, although the population of the latter is much greater. There is an interesting sidelight on this problem from the Registrar General's Tables on causes of death from 1952 to 1954 (Registrar General, 1953-55). Influenza is infrequently given as a cause of death from respiratory disease, the main ones being given as pneumonia and bronchitis. With these the crude rates between 1952 and 1954 seem to indicate that pneumonia deaths were particularly prevalent in the Liverpool area (Merseyside) and bronchitis deaths in the Manchester area (South Lancs.). The question whether a real difference exists in the respiratory disease experience of soldiers from Liverpool and Manchester must be left for future confirmation.

In considering Table I and Fig. 1, it should be remembered that certain occupations were exempt from National Service, for example coalmining, and, therefore, in certain localities the National Service pattern may not be representative of the local risks in so far as these are occupational. (There may of course be indirect risks from living in the same area, or from being a member of the family).

Influence of the Place where the Serviceman WAS Stationed.- It might be argued that the method used has only apparently eliminated the effect of the present station, and that there could be a connexion with the former home, say in the possibility of being called up to the depot of a county Regiment, somewhere in the same region. The extent of this is, however, limited since it applies only to some infantry units, and then only in the first months of training.

A more likely influence may be found in the circumstance of spending leave at home-not in having a short illness at home, for that would have gone unrecorded-but in returning with an infection which developed subsequently. This cannot apply to that substantial proportion (one-third) of respiratory illnesses which developed overseas. Its effect in the United Kingdom cannot be assessed, but it probably does exist.

There is no readily available source of national morbidity statistics which would be suitable for measuring respiratory illness in those areas, generally non-urban, where the soldiers were stationed, though some studies that have been made are relevant and are discussed in the final section. The summary in Table II of such illness among soldiers probably reflects civilian experience to some extent, especially with regard to influenza. It is taken over the whole period from 1950 to 1956, and includes regular soldiers as well as National Servicemen.

TABLE II

AVERAGE NON-STANDARDIZED ADMISSION RATES PER 1,000 FOR RESPIRATORY DISEASES AMONG SOLDIERS FROM 1950-56, IN DIFFERENT AREAS OF THE UNITED KINGDOM

\begin{tabular}{|c|c|c|c|c|c|}
\hline \multirow[b]{2}{*}{ Command } & \multicolumn{5}{|c|}{ Rates per 1,000} \\
\hline & $\begin{array}{l}\text { Tonsillitis } \\
\text { and Phar- } \\
\text { yngitis }\end{array}$ & $\begin{array}{l}\text { Com- } \\
\text { mon } \\
\text { Cold }\end{array}$ & $\begin{array}{l}\text { Influ- } \\
\text { enza }\end{array}$ & $\begin{array}{l}\text { Bron- } \\
\text { chitis }\end{array}$ & $\begin{array}{l}\text { Pneu- } \\
\text { monia }\end{array}$ \\
\hline $\begin{array}{lc}\text { Eastern } & \ldots \\
\text { Southern } & \ldots \\
\text { Western } & \ldots \\
\text { Northern } & \ldots \\
\text { Scottish } & \ldots \\
\text { Northern Ireland }\end{array}$ & $\begin{array}{l}36 \cdot 1 \\
32 \cdot 2 \\
49 \cdot 3 \\
42 \cdot 3 \\
33 \cdot 6 \\
32 \cdot 8\end{array}$ & $\begin{array}{l}16 \cdot 8 \\
23 \cdot 2 \\
26 \cdot 0 \\
29 \cdot 9 \\
29 \cdot 2 \\
25 \cdot 6\end{array}$ & $\begin{array}{r}16.4 \\
11.6 \\
25.5 \\
8.3 \\
10.0 \\
3.8\end{array}$ & $\begin{array}{r}9.1 \\
6.7 \\
11.2 \\
7.6 \\
10.8 \\
9.6\end{array}$ & $\begin{array}{l}4 \cdot 3 \\
3 \cdot 2 \\
4 \cdot 2 \\
4 \cdot 3 \\
4 \cdot 1 \\
2 \cdot 9\end{array}$ \\
\hline
\end{tabular}

The commands, at that time, corresponded roughly as follows to the regions used in Fig. 1 for grouping the Boards for examination on enlistment: roughly speaking the Army's Northern Command corresponded to the North-East region; Western Command included Wales, the North-West, and Midland regions; Southern Command included the South-West and South regions; and Eastern Command included the South-Eastern, London, and East Anglian regions.

Comparisons between the commands are not quite straightforward as the admission rates may reflect certain differences in medical administration. An improved basis for comparison is in relation to the injury rate in each command. In Fig. 2 (overleaf), the rates for each command are expressed as percentages of the injury rate and are plotted on a logarithmic scale so that proportional variations appear constant at different morbidity levels. The level for the United Kingdom as a whole is also shown.

A rough basis for judging the variation between commands is to take a quarter of the rate for each disease in the larger commands, half the rate in Scotland, and three-quarters in Northern Ireland. Anything outside these limits is marked in Fig. 2.

The most substantial variation was in influenza, which was highest in Western Command. This command was also high in all respiratory diseases.

If now we suppose that the experience at these Army stations was related to the local civilian experience, Tables I and II seem to show that illness in soldiers who formerly lived in certain areas was in some degree connected with the level of current infections there. Scotland is the maior exception. 


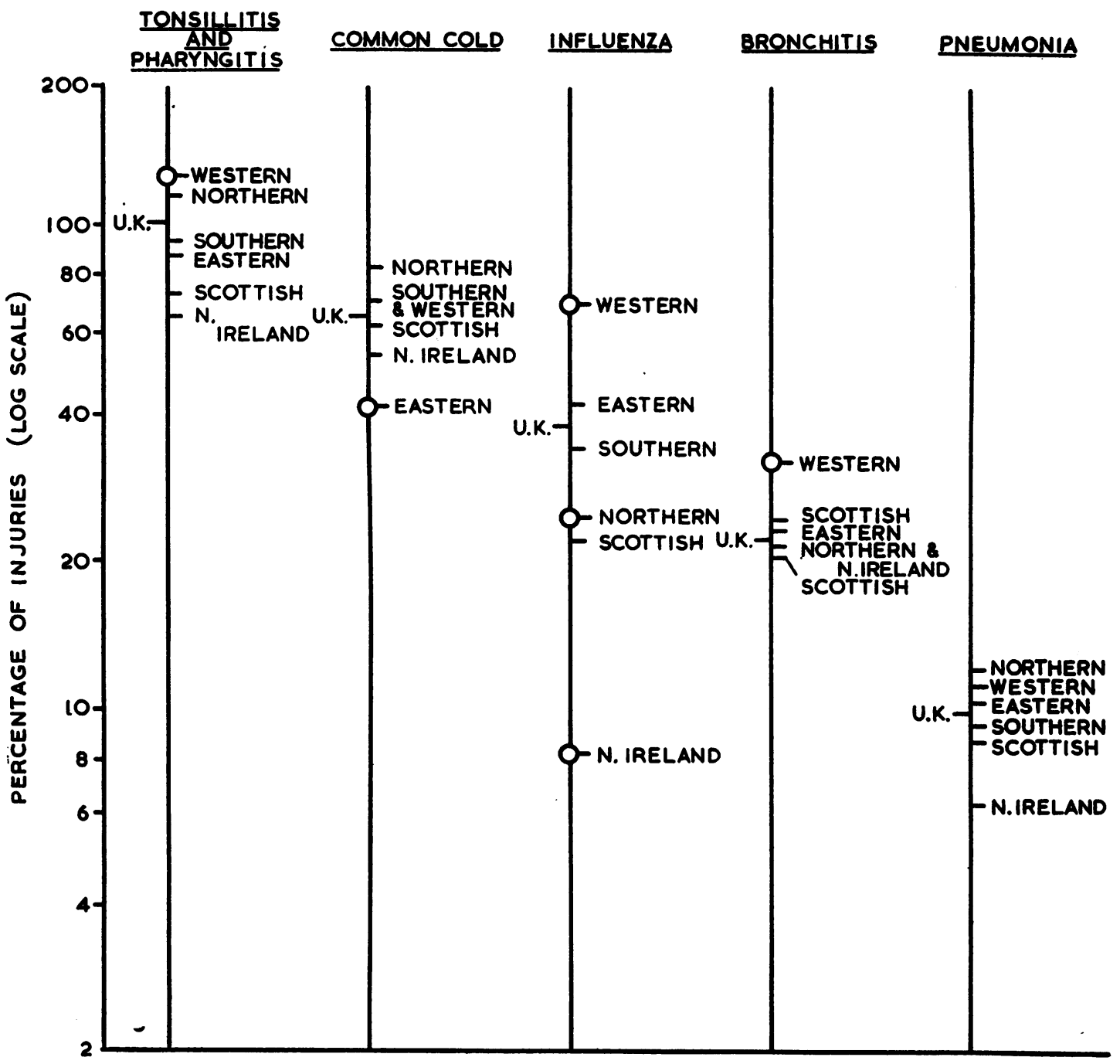

Fig. 2.-Average admission rates per 1,000 for respiratory diseases among soldiers from 1950-1956, expressed as a percentage of injuries in each Command of the United Kingdom on a logarithmic scale.

LeNGTH OF SeRvice.-The shorter the interval since call-up, the greater would seem to be the likelihood that previous conditions at home could make the soldier liable to suffer from respiratory disease. On the other hand, while it is well known that the risk is greatest in the earliest months of service, this is commonly attributed to cross-infection between recruits. For example, Dudley (1926), discussing airborne disease in recruiting depots, attributed the high incidence to the rapid turnover in population and pointed to the sleeping quarters as the most likely place of spread. The effect is demonstrated in Table III (opposite), which is based on cases for 1954. Tables such as this were first derived in a previous paper (Rosenbaum, 1959) where they were described in detail.

Table III also reveals an age effect after the recruit stage, even at equivalent lengths of service (which terminated at 2 years), to the extent of doubling the rate among the younger soldiers. This can hardly be 


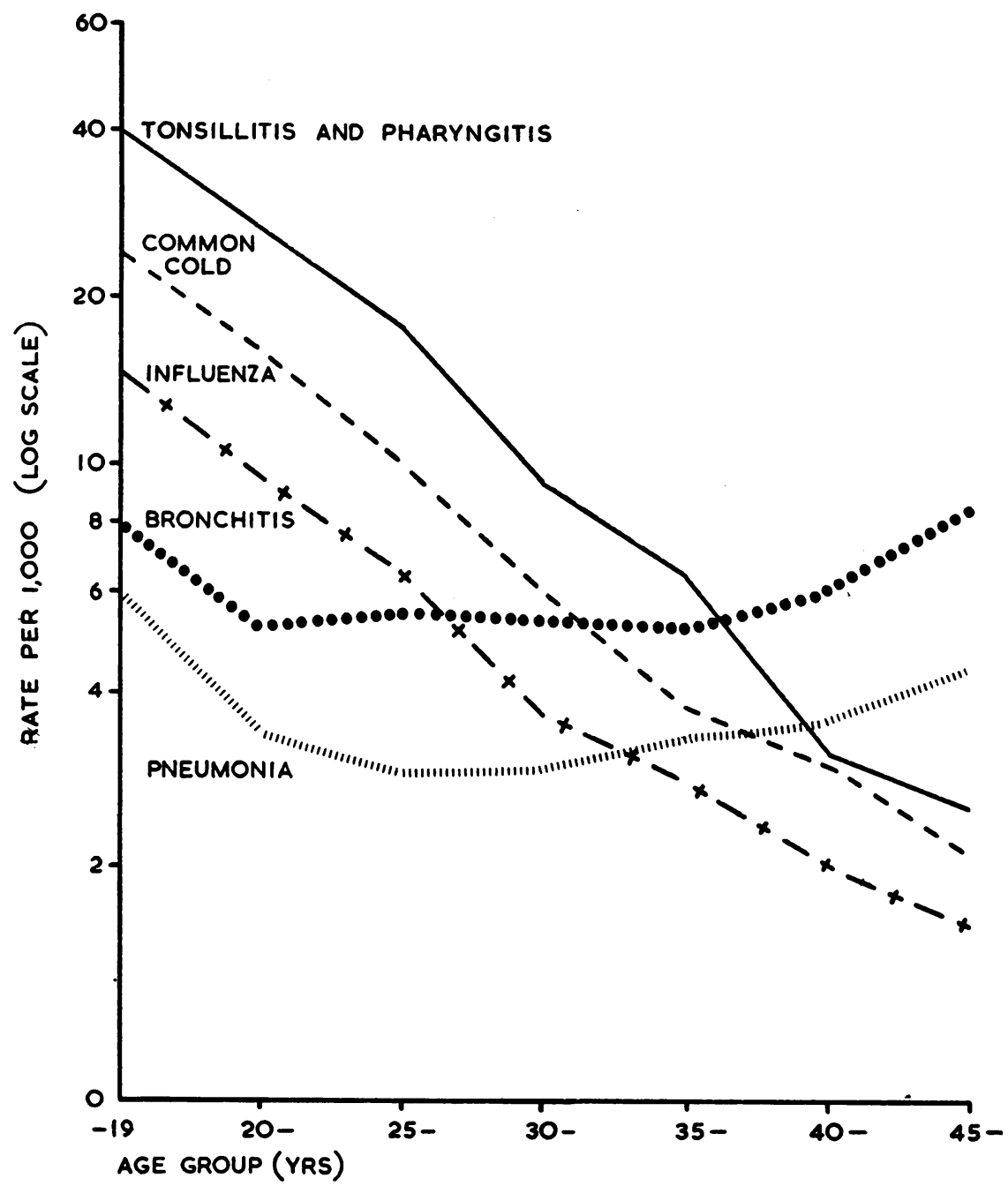

FIG. 3.-Admission rates per 1,000 for respiratory diseases among soldiers in the United Kingdom averaged over 1951 to 1954, and expressed by age groups on a logarithmic scale.

TABLE III

ADMISSION RATES PER 1,000 FOR RESPIRATORY DISEASES AMONG NATIONAL SERVICEMEN IN THE UNITED KING-
DOM, 1954, BY VARIOUS COMBINATIONS OF AGE AND DOM, 1954, BY VARIOUS COMBINATIONS
LENGTH OF SERVICE

\begin{tabular}{c|c|r|r}
\hline \multirow{2}{*}{ Age Last Birthday (yrs) } & \multicolumn{3}{|c}{ Length of Service (completed months) } \\
\cline { 2 - 4 } & \multicolumn{1}{|c|}{$0-$} & \multicolumn{1}{c}{$3-$} & \multicolumn{1}{c}{$12-$} \\
\hline Up to 18 & $* 135 \pm 21$ & $* 127 \pm 21$ & \\
19 & & $53 \pm 8$ & $75 \pm 10$ \\
\cline { 2 - 4 } 20 and Over & $114 \pm 23$ & $65 \pm 10$ & $* 36 \pm 4$ \\
\hline
\end{tabular}

* Rates which depart significantly from the average in an overall test. accounted for entirely by a difference in age of 2 to 3 years.

There is indeed an effect of age over the whole range of ages represented in the Army, and the fitting of trends, discussed in the Reports on the Health of the Army for 1954 (1958) and 1955 (1959), indicates that, for the larger groups of respiratory diseases, there is a constant proportional decline in the rates with increasing age; in other words their logarithms lie nearly on a straight line. This is demonstrated in Fig. 3, which gives rates for soldiers of all ages in the United Kingdom, plotted on a logarithmic scale. 
The more exaggerated trend of Table III is likely to be related to home background in a different way from that discussed previously. It probably follows from the fact that the older National Serviceman had had his service deferred as an apprentice or student and was more likely to have come from a healthy environment and to have enjoyed a higher standard of living. This could still be true within the larger regional pattern.

Though leave was mentioned in the previous section, it might be thought irrelevant for the recruit because of the demands of training. Nevertheless week-end passes were probably issued quite often when home was near, and might have served to enhance the infection rate.

\section{Discussion}

The regional incidence of respiratory diseases among soldiers is likely to be paralleled among civilians who live in the same, on the whole nonurban, areas. This seems fairly clear as regards influenza, though with other diseases it has not been possible to obtain precisely comparable morbidity figures for civilians. The nearest are those obtained for general practices in England and Wales from May, 1955, to April, 1956, by Logan and Cushion (1958). These are for males and females of all ages, and not surprisingly the types of respiratory disease are differently distributed from those of soldiers. The strongest resemblance lies in the high figures for the North-West and Midlands. Unfortunately this study did not extend to Scotland. Both these authors and Fairbairn and Reid (1958), in their analysis of postmen (which did include Scotland), found an effect due to living in urban surroundings.

The attempt has been made in this paper to eliminate the effect of the region where a soldier was serving, in order to assess the continued influence of his home background. This has been done by taking note of where he lived before being called up, and relating cases of respiratory disease to the numbers at risk from each locality. A pattern emerges suggestive of greater liability to respiratory diseases in people from the industrial areas of the country. Questions which arise are whether the results are indicative of life-long conditioning or reflect recent local epidemics at home, and whether in the latter case there was a carry-over from these or an acquired immunity. The greatest incidence was in recent recruits, suggesting a susceptibility on entry into the Army. Perhaps the young man from an unfavourable environment was still influenced by its disadvantageous effects for a short while; otherwise, one might have anticipated that the higher incidence would be among those from the risk-free areas, which was not the case.

Although National Servicemen from certain industrial areas had a poorer prospect for the development of respiratory disease in the Army, it was not so for everyone from those areas, since deferred men did better. These would be mainly apprentices and students who would tend to come from homes with a higher standard of living and accommodation. Also they would be less exposed to risk while on leave.

The device of hinging the analysis on home locality tended also to make the results independent of standards of diagnosis and treatment, which might vary with the region. Even though standards in the Army are reasonably constant from place to place, and probably more so than in civilian practice, it is evidently an advantage to eliminate this source of variation too.

To say that an industrial background was incriminated is to judge by high rates in Scotland, the Midlands and the North, and London. Scotland had the highest rate $(30$ per cent. above the national average) and owed this position to National Servicemen who had come from Glasgow. Next among the big towns, and not far behind Glasgow, was Liverpool. In contrast, civilian death rates published by the World Health Organization (1958) show the respiratory deaths for Scotland to have been decidedly lower than for England and Wales in 1955 , though of course they reflected the rates, mainly of bronchitis, among the elderly.

Within England and Wales there is a general agreement with the distribution given in the Registrar General's "Decennial Supplement on Area Mortality" (Registrar General, 1958) based on the years 1950 to 1953, but some variation in detail. Reid (1958) picked out polluted fog as an important element in bronchitis deaths; and it may be that Manchester, where the death rate for chronic bronchitis is very high, has a foggier climate than either Liverpool or Glasgow (Meteorological Office, 1952). There may be some disagreement over this (Fairbairn and Reid (1958) list Liverpool and Manchester together), but certainly the air of all three cities is heavily polluted (Brooks, 1954); Liverpool, with its concentration on commerce rather than manufacturing, is perhaps best off in this respect.

In contrast to deaths from chronic disease the present study shows acute respiratory illnesses to have been more common among young people from Glasgow and Liverpool, perhaps due in part to overcrowding, or to importations of influenza through the ports. The inference must be that liability to acute respiratory infections in the young 
is not in itself a sufficient prologue to serious illness in later life.

It has to be considered why the regional differences should have persisted in soldiers who had left home. They would be entitled to periods of leave when they could be infected. But leave is unlikely to have been granted frequently during the first 3 months of service when infections were most common. They could bring the infection with them when called up, but that would imply longer periods of incubation than are usually accepted for these diseases; further light would be shed on this question if it were known for each component disease, such as the common cold or tonsillitis, whether there was the same regional effect, but more extensive data would be needed. Finally there is the possibility that soldiers from certain localities were more susceptible through having a lower resistance.

\section{SUMMARY}

The incidence of respiratory disease in National Servicemen has been correlated with their home localities before call-up and it appears that the possession of an industrial home background (judged by large geographical regions) had an adverse effect on subsequent illness during National Service. Scotland (particularly Glasgow) was the worst area, and East Anglia the best in this respect (together with the South and South-West of England). The method that has been used appears to eliminate the effect of the present station, where respiratory illness probably resembles the local civilian pattern.

The most likely factors in the situation seem to be a lower resistance in those from certain localities and the acquisition of infection on leave. The recruit also may have brought the infection with him, possibly an important element since the highest incidence was among recruits.
Later on in service those who had been deferred appeared to suffer less from respiratory disease than others. This might be an added argument for inherent resistance, though also, such people on leave will have been less subjected to the risk of infection.

\section{REFERENCES}

Brooks, C. E. P. (1954). "The English Climate". English Universities Press, London.

Dudley, S. F. (1926). Med. res. Coun. spec. Rep. Ser., No. 111

Fairbairn, A. S., and Reid, D. D. (1958). Brit. J. prev. soc. Med., 12, 94.

Logan, W. P. D., and Cushion, A. A. (1958). "Morbidity Statistics from General Practice. Volume I. General". General Register Office Studies on Medical and Population Subjects, No. 14. H.M.S.O., London.

Meteorological Office (1952). "Climatological Atlas of the British Isles". Air Ministry, M.O. 488. H.M.S.O.

Registrar General (1953). "Statistical Review of England and Wales for the Year 1952". Tables, Part I. Medical. H.M.S.O., London.

(1954). "Statistical Review of England and Wales for the Year 1953". Tables. Part I. Medical. H.M.S.O., London.

(1955). "Statistical Review of England and Wales for the Year 1954". Tables .Part I. Medical. H.M.S.O., London.

(1958). "Decennial Supplement. England and Wales, 1951". Area Mortality. H.M.S.O., London.

Reid, D. D. (1958). Lancet, 1, 1289.

Rosenbaum, S. (1959). Brit. J. prev. soc. Med., 13, 103.

War Office (1958). "Report on the Health of the Army for 1954". W.O. Code No. 11709.

(1959). "Report on the Health of the Army for 1955". W.O. Code No. 12369.

World Health Organization (1949). "Manual of the International Statistical Classification of Diseases, Injuries, and Causes of Death, 1948". H.M.S.O., London.

(1958). "Annual Epidemiological and Vital Statistics, 1955". W.H.O., Geneva. 